\title{
Optimization of Continuous Airworthiness Problems
}

\author{
Qusay Hassan $^{1,2}$, Kamila kustron ${ }^{3}$, Marek Jaszczur $^{1}$ and Mazin Ajaweed ${ }^{4}$ \\ 1. AGH University of Science and Technology, Faculty of Energy and Fuels, Poland \\ 2. University of Diyala, Department of Mechanical Engineering, Iraq \\ 3. Warsaw University of Technology, Faculty of Power and Aeronautical Engineering, Poland \\ 4. Baghdad University of Technology, Department of Control Systems Engineering, Iraq
}

\begin{abstract}
Recently aviation accident data shows that many fatal accidents in aviation are due to airworthiness issues despite the fact that all civil and private aircraft are required to comply with the airworthiness standards set by their national airworthiness authority. This paper presents a unique approach to continuous airworthiness problems optimization needed to reduce the risk associated with the gap between aircraft designers \& manufacturing organization and continuing airworthiness (state of civil aviation authority and air operators). As a result of the paper summarizes these problems and searching of the possible solutions to be optimized, these problems are achieved to get more integration between (designers\& manufacturing and air operators), finally the recommendations are drawn to address the safe operation of the aircraft and can be given to the International Civil Aviation Organization (ICAO), Federal Aviation Administration (FAA) and European Aviation Safety Agency (EASA) and Civil Aviation Authorities (CAAs) for more integration between all of them structure.
\end{abstract}

Key words: Airworthiness, optimization, aviation safety.

\section{Introduction}

The 1929 Warsaw convention was adopted when long range civil aviation barely existed. It entered into force on 13 February 1933. The purpose of the 1929 Warsaw convention was the "Unification of Certain Rules for the International Carriage by Air" for the time in the future when passengers and good would be transported worldwide [1]. Now we have the base of aviation rules consist of 18 Annexes as Standards and Recommended Practices, many amendments and Annex 19 which will be legislated in November. ICAO policies on competition are still valid, based on observed practices, such as the inclusion of ICAO model clauses on competition in air services agreements [2]. While there are significant differences between competition policies adopted by different regions, a number of common types of anticompetitive practices could be tentatively identified. Based on existing ICAO guidance, as well as on practices and

Corresponding author: Qusay Hassan; corresponding qusayh@uodiyala.edu.iq. rules observed in a broad sample of States and regions, the most prominent anticompetitive practices in air transport could be further analysed and more precisely defined. Those common elements could form the basis for the development of a set of core principles on fair competition in international air transport [3].

The process to unify aviation regulation should develop according to all areas of aviation due to having the same base. In this paper recommendation for airworthiness,system has been recognized.The international continuing airworthiness system is essentially a complex communication system among all of the organizations responsible for the design, manufacture, regulation, operation, and maintenance of a transport aircraft type. To ensure the maximum reliability of the system, it is necessary to have correct knowledge and control of the system at all levels. It is also necessary to ensure that the procedures that the system depends upon are clear, relevant, workable, and resistant to human error, as well as there, are many different components to the system, each with their own particular characteristics and complexity, the 
system requires robust defences to ensure that continuing airworthiness assurance is maintained [4,5].

The operator is the focus of this communication system. They are both the initial source of much of the raw data that drives the system, as well as being the eventual recipient of the continuing airworthiness information that the system produces [6]. The framework for these information flows between states, manufacturers/designers, and operators are outlined in ICAO Annexes: 6 and 8. Fig. 1a indicates the flow of raw data from the operator to the state of registry and the manufacturer/designer (blue colour), and the flow of the resulting continuing airworthiness information back to the operator (orange colour) [7]. The complete ICAO framework for the international continuing airworthiness system is shown in Fig. 1b [7, 8].

Under the ICAO defined system, the design organization receives in-service data from operators. It then develops safety-related service information based on that data. The design organization has no power to mandate the service information it provides to operators, so that information is, in that respect, advisory [9]. The design organization can, however, categorises the information with respect to its urgency and relevance to flight safety. That standard requires

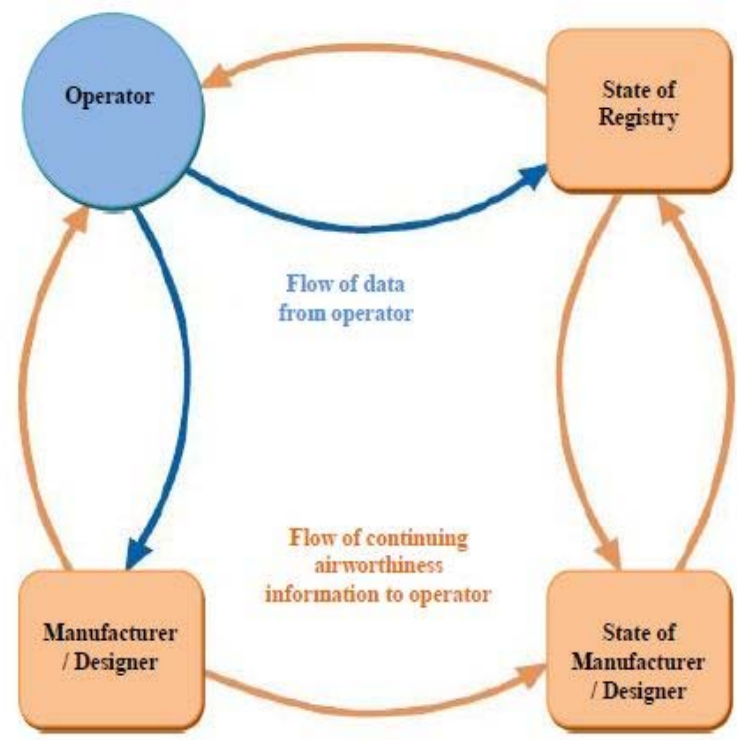

(a) that a system is established for ensuring that operators receive all relevant information from the design organization and act on it appropriately. The system has to be in accordance with a procedure acceptable to the state of registry, which implies a degree of oversight by the state of registry [10-13].

\section{Enhancement Monitoring Information}

A robust system must monitor the quality of its inputs to be confident that it can produce a high-quality output. The continuing airworthiness system is no exception. We recognized two cases. The 1 st case is if the state of the registry is assured that it can provide the necessary mandatory continuing airworthiness information to operators. It needs to be confident that the information which is received from the state of design is complete, accurate, and timely. The state of the registry can achieve this by monitoring the continuing airworthiness information from the designer/manufacturer that the state of design uses to prepare its output. Fig. 2, where the dashed line indicates a mechanism by which a state of the registry can satisfy itself of the quality of the mandatory continuing airworthiness information it receives from states of a design.

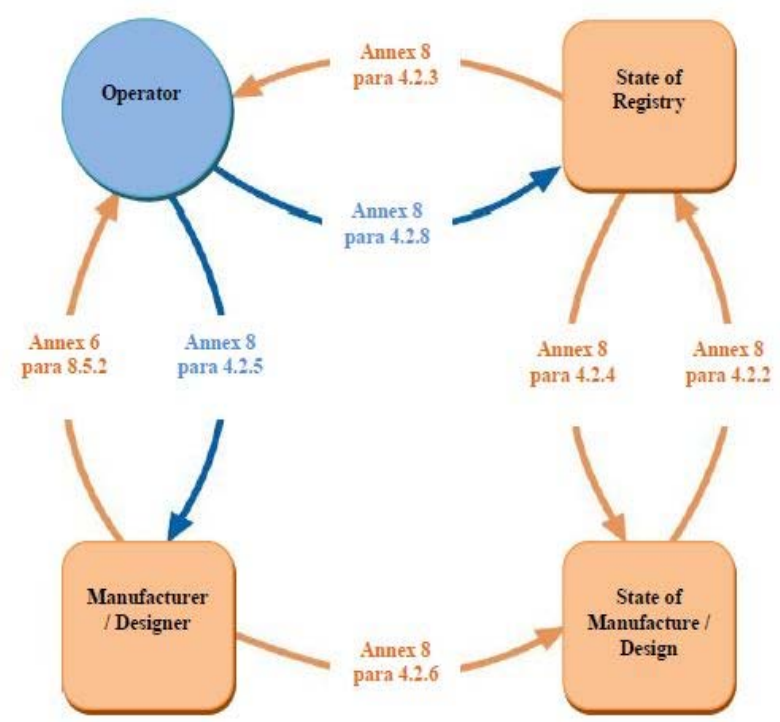

(b)

Fig. 1 Information flows associated with continuing airworthiness between each "players" (a), reference to the relevant paragraphs (b), [7,8]. 


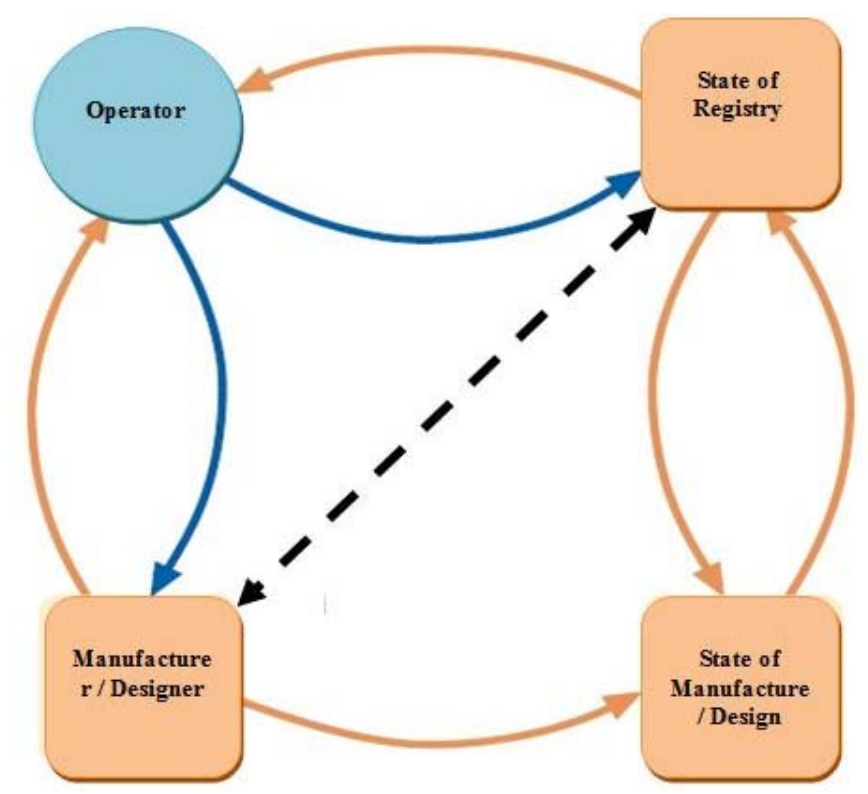

Fig. 2 More robust system for continuing airworthiness information flows.

The $2^{\text {nd }}$ case which is shown inthe Fig. 3 outlines a system with multiple mechanisms to enhance resilience. The flow of information starts from the operator as a service difficulty and returns to the operator as continuing airworthiness information. The central arrows show the flow of information, the green arrows show confirmation of information transfer, and the black arrows show the process of quality assurance of the received information.

\section{Continuous Airworthiness Problems}

Continuous airworthiness problems are divided into two main parts associated with the designer/ manufacturer problems and air operator problems (civil aviation authority and airlines maintenance) as shown below in Fig. 4.

\subsection{Designer and Manufacturer Problems}

The main designer/manufacturer problems are listed below:

- The designers and manufacturers apparently are not making themselves aware of all unsafe conditions which arise, as is required of them by certification rule. This is evident in the fact that there are numerous aircraft out there with given by FAA or EASA approved parts installed for which airworthiness directives have been issued. In Airworthiness Directive must be definition issued to correct an unsafe condition [14-16].

- There is a huge inconsistency as to what a "Safety Directive" actually. All aircraft require compliance with safety directives issued to correct unsafe conditions. This language seems to make evident the fact that safety directives can only be legally required when issued to correct unsafe conditions. Standard Practice for continued operational safety monitoring of aircraft [17, 19].

- There is no reliable data base system for safety directive research. Many manufacturers have very comprehensive web sites dedicated to supporting their machines. This is a step in the right direction, although it is still largely lacking, and it does not mention anything about manufacturers that do not provide access to quality technical support $[18,19]$.

- If Airworthiness Directives requires any form of alteration to the product for which it is issued, legally speaking, prior aircraft manufacturer approval would be necessary. The manufacturer could simply issue a safety directive to transmit the airworthiness directives (as should be done), including the approval for the alteration, and the problem would be solved. But this is not happening $[18,19]$. 


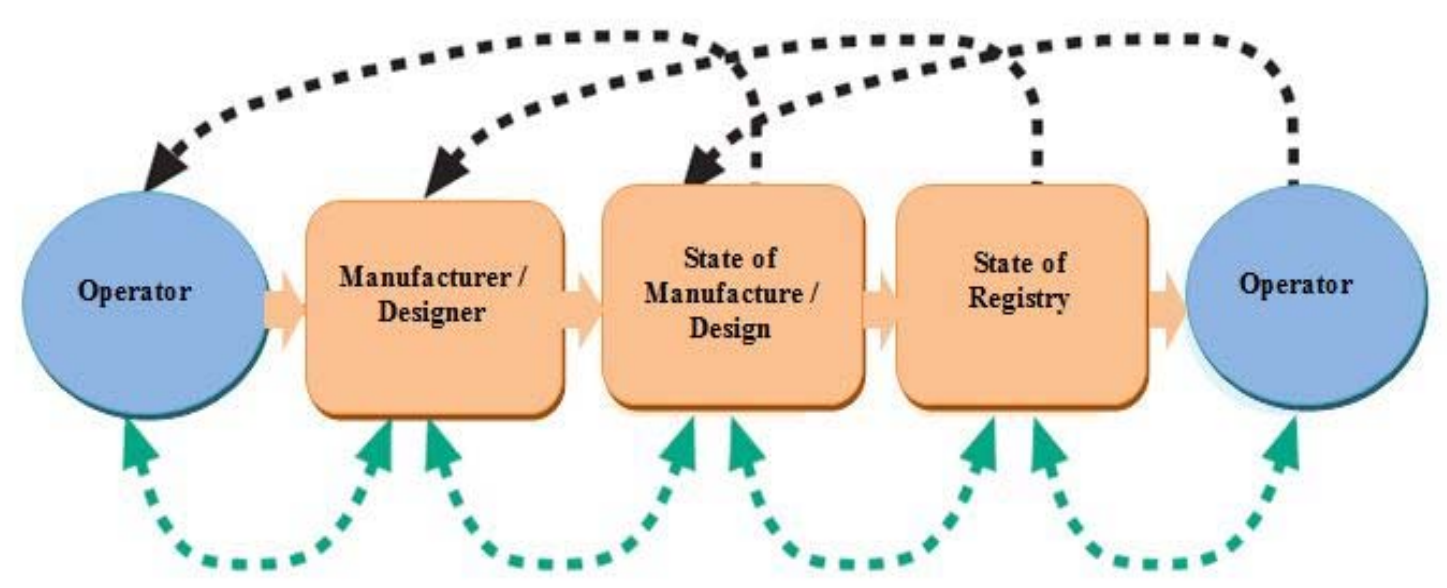

Fig. 3 Mechanisms that can enhance the resilience of information transfer.

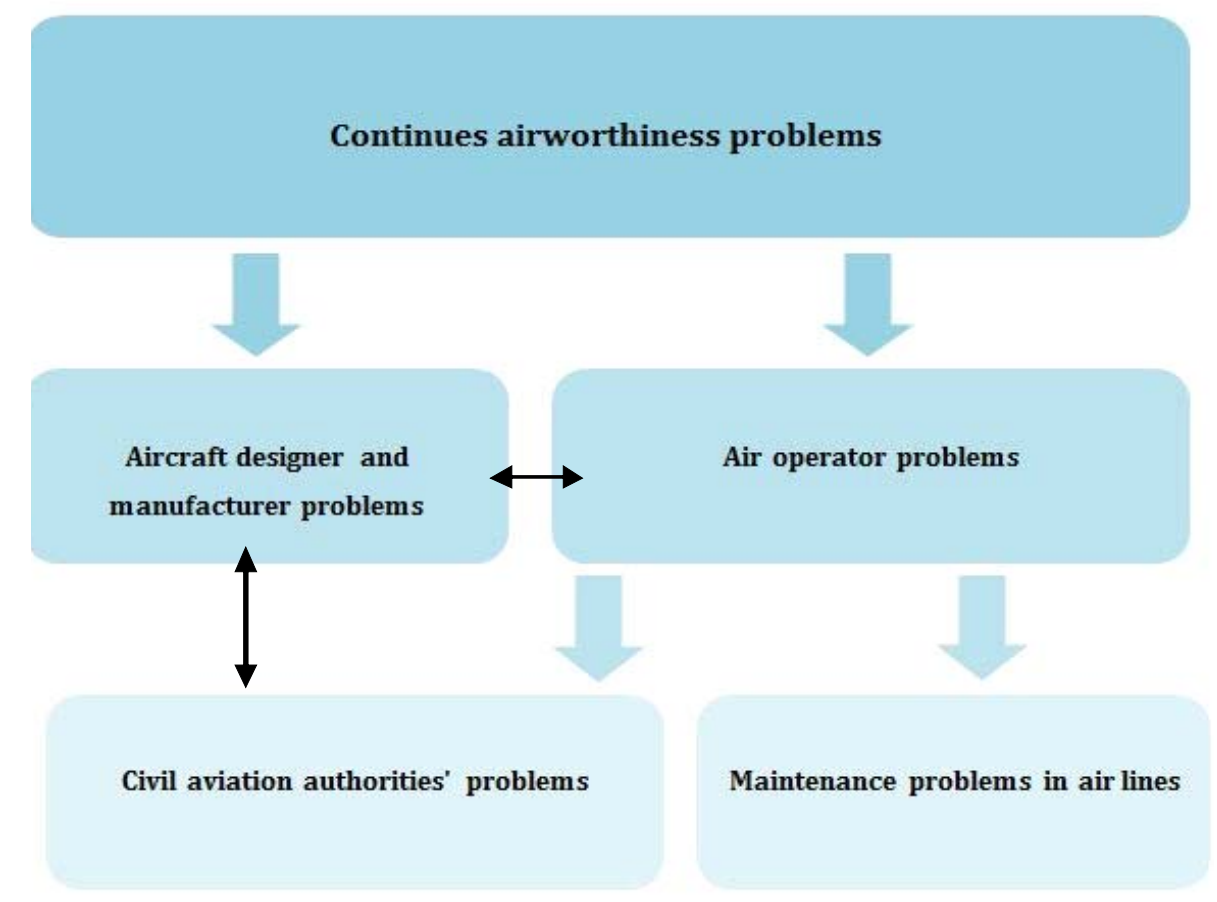

Fig. 4 Continuous airworthiness problems diagram.

- The need for more overlap in regulations, airworthiness codes, policies, procedures, organizational structure, activities, standard andcommunications between FAA and EASA for the import, export, and continued support of civil aeronautical products.

The possible ways to optimize these problems are: (1) FAA and EASA must use the same procedures for the initial design approval of each other's products and appliances; (2) FAA and EASA must use the validation process based on the type validation principles; (3) FAA and EASA shall also use a simplified validation process when issuing an appliance approval.; (4) The FAA and EASA must use standard communication between both of them.

The FAA and EASA should see to it that aircraft 
manufacturers are making themselves aware of existing and potentially unsafe conditions that might already be reflected as airworthiness directives, and that safety directives are issued to transmit awareness of those conditions to the aircraft in the world.

Manufacturers need to accept the responsibility imposed upon them by certification rule to keep track of safety issues affecting all of the installed components in their aircraft manufactured by others, not just the airframe that they, themselves, have produced. To discharge this responsibility effectively, the aircraft manufacturers need to remain in close contact with their vendors and operators of installed components [20-23].

\subsection{Air Operator Problems}

There are two fields of problems according to Air Operator issue: the Civil Aviation Authorities problems and airlines maintenance problems, as shown in Fig. 3. Currently, the Civil Aviation Authorities in the world is the only one method of determining what deficiencies are there in maintenance data which is reviewed reportable events and seek experiences from surveyors in the aircraft maintenance standards department and the design and production standards division [24]. At the time of this review, the following problems were identified as producing the maximum information on any insufficient information for the continued viability of aircraft in air operators [24]:

- Mandatory Occurrence Report (MOR). The civil aviation authorities in the world receive a very large number of MOR each year that have indicated a hazard to the aircraft. Unfortunately, most of the civil aviation authorities do not send these reports to the aircraft manufacturing and designer companiesin order to do correction of these defects.

- Service Bulletins (SB) and Airworthiness Directives (AD). Poorly written $\mathrm{AD}$ and their associated SB are something that again, most of the maintenance community has experienced. From a continuous airworthiness perspective, these are important as they frequently address known hazards and the effect of failing to meet the modification or inspection objective will almost certainly affect safety. Whilst no database is available to track and identify these, various departments in the civil aviation authorities performed a review of those known airworthiness directives and service bulletins which failed to control the risk. A surprising number were identified including such things as, tasks unable to be performed as written, critical steps omitted, environmental conditions not stated and poor inspection standards. These indicate to the Civil Aviation Authorities that the system for producing such data requires improvement.

- Air accidents investigation and recommendations. The civil aviation authorities must perform a review of the accident reports from the Air Accidents Investigation Branch (AAIB) in order to identify where errors and omissions in maintenance data contributed to or caused the event. The review also looked to see how often the aircraft maintenance programmes was deficient, as opposed to just the maintenance data used by maintenance personnel. This indicated that data errors, such as incomplete, ambiguous, or inaccurate information were far more numerous than deficient aircraft maintenance programmes. In view of the efforts made, the requirements for review by aircraft operators and direct civil aviation authorities involved in approving maintenance programmes may not be surprising.

The possible ways to optimize these problems and recommendations to CAAs and Air Operators.

The recommendations forming the basis of the CAAs in the world are:

- Where a service bulletin is issued to address a hazard severe enough to warrant mandatory airworthiness directive action, the service bulletin should be verified and validated by the manufacturer and approved by the CAAs.

- A condition of a design organization approval should include the requirement to keep any 
documentation to support continued airworthiness up to date.

- Determine the potential benefits of enhancing the process for the approval of equipment by specifically including the investigation of the provision of Information for continued airworthiness.

- Perform a cost/safety benefit study of the various options for mandating manufacturer verification and validation of the information for continued airworthiness, or part thereof, and the appropriate level of CAAs oversight. This would include the scope of maintenance review board activities.

The maintenance problems are very important in Air Operator due to most problems of the airworthiness are discovered by maintenance team, which can be summarized as: "Maintenance mistakes problems is very important problem it's threats to the airworthiness of an aircraft and they will probably mention mental fatigue, corrosion, excessive wear of components or other results of ageing and use, and beside these problems the human errors, and the frustration, sleepiness, misunderstandings and memory lapses which produce them, are powerful forces affecting the quality of maintenance and hence the airworthiness of aircraft. According to Boeing, around $15 \%$ of major aircraft accidents involve maintenance error [4].

The most important of the maintenance organizational problems are:

- Lack of refresher training. The regulations state that maintenance personnel must receive proper and periodic instruction. However, in reality, a few maintenance engineers receive refresher training once they have gained their licenses. Without such training, non-standard work practices can develop or engineers can lose touch with changes in regulations or company procedures. One senior airline manager put it this way: (maintenance engineers are like torque wrenches: they need to be re-calibrated from time to time).

- Lack of learning from incidents. The conventional wisdom among safety experts is that for every accident there may be 30 or more previous minor incidents.
Unfortunately, we do not always learn the right lessons from these warning Incidents sometimes because they are never reported. It is never easy to admit a mistake; however, it is even harder when an origination punishes people who make honest mistakes perhaps by docking pay or placing notes on personnel files. A punitive culture within the company or the regulatory authority creates an atmosphere in which problems are quietly corrected and places barriers in the way of learning from our mistakes.

- Fatigue. There is probably no way to avoid the need for maintenance to be done at night; however, this does not mean that fatigue levels cannot be managed. Unfortunately, almost all night-shift workers suffer from a lack of quality sleep. The possible ways to optimize the problems can summaries: (1) to introduce refresher training, particularly on company policies and procedures, (2) to introduce a clear responsibility policy to remove barriers that discourage people from reporting incidents, 3) to introduce a fatigue management program (it will almost certainly involve ensuring that workers get adequate sleep opportunities; if 12-hour shifts are being worked, a ban on extending shifts with overtime may be necessary), (4) to introduce human factors training for management and workers and (5) to minimize the simultaneous disturbance of multiple or parallel systems.

- The gap between the maintenance and production program is the maintenance organization between airworthiness and maintenance, and the problems caused by a misunderstanding of the relationships within the approval system vary, many and exist at all levels within the organizations. The operator does not provide the information to the desert organization at the time or at the launch, a technician who said that the limits of the bananes are only limited and that the deviation can be seen in the building of experience. Such mindsets can be argued to result from insufficient awareness of how the system is designed to operate. Maintenance activities that contribute to airworthiness must be performed by Approved Maintenance 
Organizations. It must, therefore, be clear and unambiguous what is required of those organizations something provided for by the contract. The possible way to improve the problem mentioned above should include many open options for industry, for example, the requirements for the aircraft maintenance license can be improved to include an aviation serviceability unit that explores the approval system, airworthiness concepts, and responsibilities. Similarly, degree courses could include the very same to capture people entering the industry via the academic route. For existing members of industry, maintenance organizations and operators could include such a module in their induction training and certifying staff could be captured either through continuation training or at authorization issue and renewal. Thus, there appears to be ample scope for the manoeuvres to bridge the gap between the viability of aircraft and maintenance, and the staff/organizations concerned.

- Human error in aircraft maintenance and inspection. Human error in maintenance usually manifests itself as an unintended aircraft discrepancy (physical degradation or failure) attributable to the actions or non-actions of the aircraft maintenance technician (AMT). The word "attributable" is used because a human error in maintenance can take two basic forms. The 1st case, the error results in a specific aircraft discrepancy that was not there before the maintenance task was initiated. Any maintenance task performed on an aircraft is an opportunity for human error which may result in an unwanted aircraft discrepancy. The 2nd case, of error, results in an unwanted or unsafe condition being undetected while performing a scheduled or unscheduled maintenance task designed to detect aircraft degradation. Examples include a structural crack unnoticed during a visual inspection task or a faulty avionics box that remains on the aircraft because the incorrect diagnosis of the problem led to the removal of the wrong box. These errors may have been caused by latent failures, such as deficient training, poor allocation of resources and maintenance tools, time-pressures, etc. They may also have been caused by the poor ergonomic design of tools [24].

Human error in the maintenance environment. There are unique characteristics which shape human error in the maintenance environment differently than in other operational environments, such as the flight deck or the ATC (Air Traffic Control) room. Push the wrong button or pull the wrong knob, issue a contradicting instruction, and the pilot or the controller will see the effects of the error before the aircraft completes its flight. If an accident or incident occurs, the pilot is always "on the scene" at the time of the accident or incident. In contrast to the "real-time" nature of the error in ATC and the flight deck, maintenance errors are often not identified at the time the error is made. In some cases, the maintenance technician making the error may never know of the mistake because detection of the error could occur days, months or years after the error was made. When a human error in maintenance is detected, usually through some system malfunction, we often know only the resulting aircraft discrepancy [24].

The possible way to solve these problems:The professional working in this field has developed various guidelines to reduce the occurrence of human error in maintenance. This section presents guidelines developed to reduce the occurrence of human error in the area of airline maintenance. Many of these guidelines can also be used in other maintenance areas as well. The guidelines cover ten areas as shown in Fig. 5. Four guidelines that cover procedures are as follows: (1) to examine work practices periodically to ensure that they do not differ significantly from actual formal procedures; (2) to examine documented maintenance procedures and practices periodically to ensure that they are consistent, accessible, and realistic; (3) to ensure that standard work practices are followed across all areas of maintenance; and (4) to evaluate the ability of checklists in regard to assisting maintenance personnel in performing routine operations. 


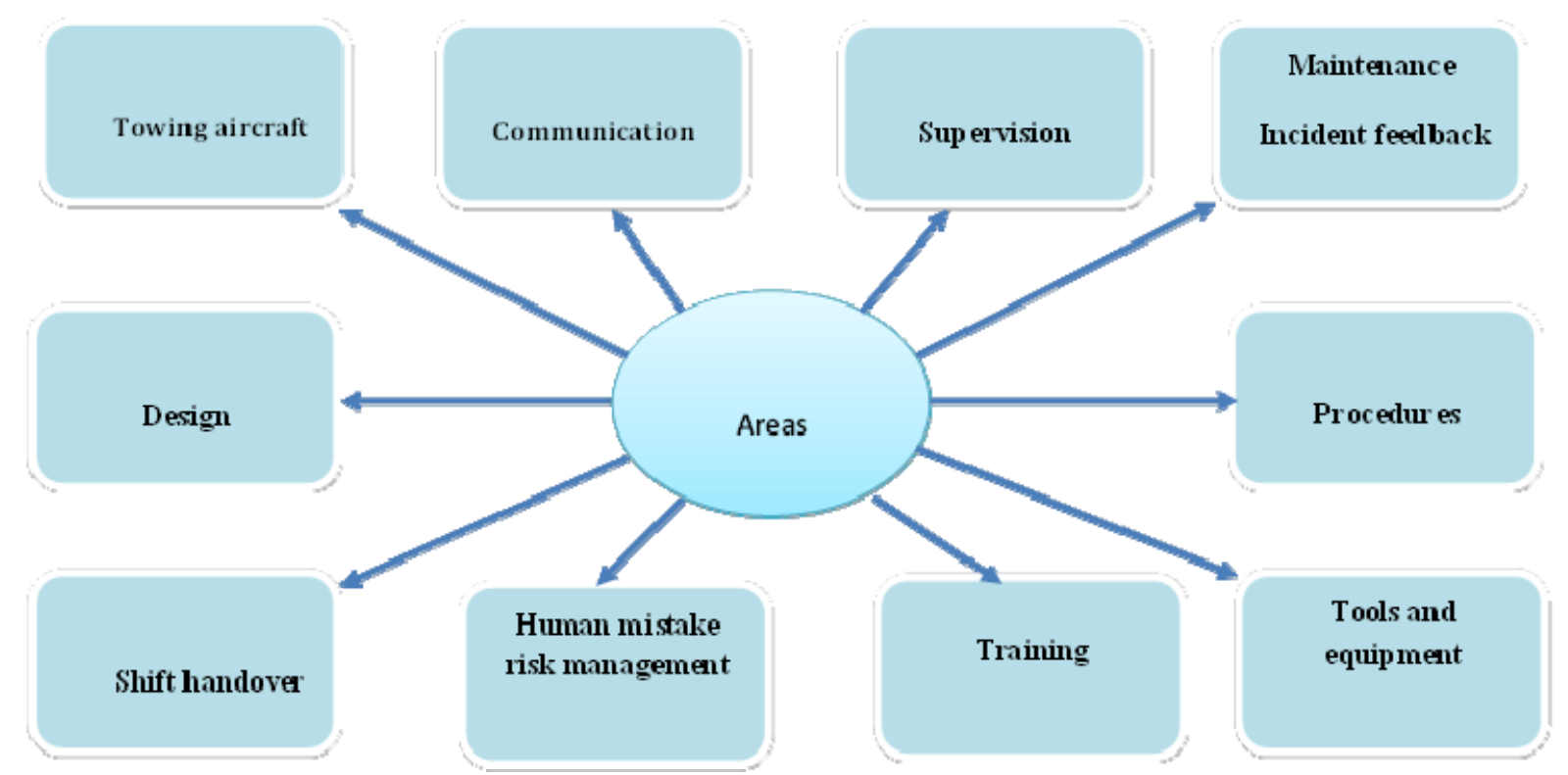

Fig. 5 Areas covered by guidelines for reducing human mistakes in aircraft maintenance activities [5, 6].

\section{Continuous Airworthiness Problems Recommendations}

\subsection{Recommendations to ICAO}

First recommendation; that the ICAO develop standards for states of the registry to ensure that there are appropriate performance measures for continuing airworthiness standards, that take into consideration: (1) the process defined in the standard; (2) a defined outcome that the standard is intended to achieve.

Second recommendation; that the ICAO develop standards for the classification and format of service information issued by aircraft, engine, and component manufacturers.

\subsection{Recommendations to FAA and EASA}

First recommendation; that the FAA\&EASA ensure that there is a defined and consistent understanding throughout the FAA\&EASA as to the importance of airworthiness directives that mandate revisions of the airworthiness limitations structural inspections for damage tolerance aircraft types, and that such airworthiness directives are processed and released without undue delay.

Second recommendation; that the FAA\&EASA ensure that adequate systems are in place to alert States of registry of designer and manufacturer aircraft types when delays in FAA\&EASA rule-making have the potential to compromise the continuing airworthiness assurance of those aircraft types.

Third recommendation; that the FAA\&EASA ensure that the identification of aircraft permitting periods to comply with the airworthiness directives is both systematic and transparent. Information on the methodology and the results used to establish grace periods, including those associated with the terms of reference, should be included for aviation, structural inspections of the types of aircraft bearing the brunt of the damage, in the notification relevant to the development of the proposed rules.

Fourth recommendation; that the FAA\&EASA must strive to resolve differences, but the decision as to the final action to be taken with respect to the products, parts, or appliances under the jurisdiction of the importing country lies solely with the importing authority following consultation with the exporting authority.

Fifth recommendation; that the FAA\&EASA must recognize the importance of the routine sharing of continuing airworthiness information as a means to 
assist in the identification and resolution of emerging airworthiness issues.

Sixth recommendation; that the FAA\&EASA must provide applicable information which it has found to be necessary for mandatory modifications, required limitations and inspections to the importing authority to ensure continued operational safety of the product, part, or appliance. The importing authority must review and normally accept the corrective actions taken by the authority representing the state of design.

\subsection{Recommendations to Civil Aviation Authorities} (CAAs)

First recommendation; that the civil aviation authorities review the effectiveness of the system for the transmission of information on faults, malfunctions and defects to the organization responsible for the aircraft's type design, in accordance with ICAO Annex 8, Part II.

Second recommendation; that the civil aviation authorities review relevant their legislation and regulations to ensure that operators of aircraft are required to have an acceptable system for receiving, assessing and auctioning safety-related service documentation, in accordance with ICAO Annex 6, Part

Third recommendation; that the civil aviation authorities develop and issue clear guidance material for, and review its surveillance of, their operators of aircraft in relation to: (1) continuing airworthiness assurance activities, including the major defect reporting system; (2) the transmission of information to the organization responsible for the type design; (3) the receipt, assessing and auctioning of safety-related service documentation.

Fourth recommendation; that the civil aviation authorities, as a part of its oversight role, review the policies and procedures for carrying out, and responding to the findings of, risk assessments of organizations that operate aircraft. The review should address the adequacy of methods for (1) gathering and assess information relevant to possible risks to safe operations; (2) determining, carrying out, and reviewing the CAAs response to the assessed level of risk.

Fifth recommendation; that the civil aviation authorities, review the structure and procedures of the major defect reporting system to ensure that: (1) defect information received is monitored, processed, and analysed; (2) defect information and information derived from subsequent investigations is disseminated to all relevant parties and made publicly available.

\section{Remarks}

The process of unification of airworthiness regulation must be intensified by cooperation between each CAAs, Air Operators as well as Designer/Manufacturer. The 18 Annexes which are the base of aviation rules must be re-edited to prepare to automatize the requirements for all "player" in airworthiness system. The recommendations gathered in the paper could be helpful in this process.

\section{References}

[1] Wassenbergh, H. A. 2013. Post-war International Civil Aviation Policy and the Law of the Air. Springer.

[2] Sulocki, T., and Cartier, A., 2003. "Continuing airworthiness in the framework of the transition from the Joint Aviation Authorities to the European Aviation Safety Agency." Air \& Space L., 28: p.311.

[3] Zhang, Y., and Findlay, C. 2014. "Air Transport Policy and Its Impacts on Passenger Traffic and Tourist Flows." Journal of Air Transport Management 34: 42-8.

[4] Dhillon, B. S. 2007. Human Reliability and Error in Transportation Systems. Springer Science \& Business Media.

[5] EASA. 2012. About EASA. Online available from http://www.easa.europa.eu/ (December 20, 2016).

[6] EASA. 2016. Continuing Airworthiness About EASA. Online available from http://www.easa.europa.eu/ (January 10, 2016).

[7] ICAO., 2010. To the Convention on International Civil Aviation. Montreal, Canada, Annex 8.

[8] ICAO. 2010. To the Convention on International Civil Aviation. Montreal, Canada, Annex 6.

[9] FAA. 20016. About FAA. Online available from http://www.faa.gov/ (November 4, 2016). 
[10] FAA. 2016. Continuing Airworthiness about FAA. Online available from http://www.faa.gov/ (January 10, 2016).

[11] De Florio, F. 2016. Airworthiness: An Introduction to Aircraft Certification and Operations. Butterworth-Heinemann.

[12] Gao, F. 2011. Continuing Airworthiness Policy and Application to Flying Crane Aircraft. A thesis of Canfield University.

[13] Kinnison, H. A., and Siddiqui, T. 2012. Aviation Maintenance Management. 2nd ed. McGraw-Hill Education.

[14] ICAA. 2016. Continuing Airworthiness about ICAA. Online available from http://www.iraqcaa.com/ (November 6, 2016).

[15] Marx, D. 1998. Learning from Our Mistakes: A Review of Maintenance Error Investigation and Analysis Systems. Washington, DC: FAA.

[16] Bureau, A. T. S. 2002. Investigation into Ansett Australia Maintenance Safety Deficiencies and the Control of Continuing Airworthiness of Class A Aircraft. Australian Transport Safety Bureau.

[17] Hobbs, A. 1997. Human Factors in Airline Maintenance:
Study of Incident Reports. Canberra, ACT.

[18] Swain, A. D. 1973. An Error-Cause Removal Program for Industry. Human Factors 15 (3): 207-21.

[19] Rodriguez, J. F. 2005. "Tort Reform \& (and) GARA: Is Repose Incompatible with Safety.” Ariz. L. Rev. 47: 577.

[20] Purton, L., Clothier, R., and Kourousis, K. 2014. Assessment of Technical Airworthiness in Military Aviation: Implementation and Further Advancement of the Bow-tie Model. Procedia Engineering 80: 529-44.

[21] Funahashi, Y. 2010. "Comparative Analysis of Aviation Safety Information Feedback Systems." Doctoral dissertation, Massachusetts Institute of Technology.

[22] Purton, L., and Kourousis, K. 2014. "Military Airworthiness Management Frameworks: A Critical Review." Procedia Engineering 80: 545-64.

[23] Technical Implementation Procedures for Airworthiness and Environmental Certification between FAA and EASA. September 2015.

[24] Wenner, C. A., and Drury, C. G. 2000. "Analyzing Human Error in Aircraft Ground Damage Incidents." International Journal of Industrial Ergonomics 26 (2): 177-99. 